\title{
Treatment Strategies for Congenital Diaphragmatic Hernia: Change Sometimes Comes Bearing Gifts
}

\author{
Francesco Morini ${ }^{1 *}$, Kevin P. Lally ${ }^{2}$, Pamela A. Lally ${ }^{2}$, Rosa Maria Crisafulli', \\ Irma Capolupo ${ }^{1}$ and Pietro Bagolan ${ }^{1}$ On Behalf of the Congenital Diaphragmatic \\ Hernia Study Group

\begin{abstract}
'Department of Medical and Surgical Neonatology, Bambino Gesù Children's Hospital, IRCCS, Rome, Italy, ${ }^{2}$ Department of Pediatric Surgery, McGovern Medical School at the University of Texas Health Science Center at Houston, Children's Memorial Hermann Hospital, Houston, TX, United States
\end{abstract}

Objective: To report treatment strategies' evolution and its impact on congenital diaphragmatic hernia $(\mathrm{CDH})$ outcome.

Design: Registry-based cohort study using the CDH Study Group database, 1995-2013.

Setting: International multicenter database.

Patients: $\mathrm{CDH}$ patients entered into the registry. Late presenters or patients with very

OPEN ACCESS

Edited by:

Kenneth Wong,

University of Hong Kong,

Hong Kong

Reviewed by:

Jorge Correia-Pinto,

University of Minho, Portugal

Go Miyano,

Juntendo University, Japan

*Correspondence:

Francesco Morin

francesco.morini@opbg.net

Specialty section:

This article was submitted

to Pediatric Surgery,

a section of the journal

Frontiers in Pediatrics

Received: 26 July 2017

Accepted: 23 August 2017

Published: 14 September 2017

Citation:

Morini F, Lally KP, Lally PA,

Crisafulli RM, Capolupo I and

Bagolan P (2017) Treatment

Strategies for Congenital

Diaphragmatic Hernia: Change

Sometimes Comes Bearing Gifts.

Front. Pediatr. 5:195.

doi: 10.3389/fped.2017.00195 incomplete data were excluded. Patients were divided into three Eras (1995-2000; 2001-2006; 2007-2013).

Main outcome measures: Treatment strategies and outcomes. One-way ANOVA, X2 test, and X2 test for trend were used. A Sydak-adjusted $p<0.0027$ was considered significant. Prevalence or mean (SE) are reported.

Results: Patients: 8,603; included: 7,716; Era I: 2,146; Era II: 2,572; Era III: 2,998. From Era I to Era III, significant changes happened. Some severity indicators such as gestational age, prevalence of prenatal diagnosis, and inborn patients significantly worsened. Also, treatment strategies such as the use of prenatal steroids and inhaled nitric oxide, age at operation, prevalence of minimal access surgery, and the use of surfactant significantly changed. Finally, length of hospital stay became significantly longer and survival to discharge slightly but significantly improved, from 67.7 to $71.4 \%$ (p for trend 0.0019 ).

Conclusion: Treatment strategies for patients registered since 1995 in the CDH Study Group significantly changed. Survival to discharge slightly but significantly improved.

Keywords: congenital diaphragmatic hernia, extracorporeal membrane oxygenation, inhaled nitric oxide, intensive care, minimal access surgery, outcome, surgery

"Change always comes bearing gifts" Price Prichett.

\section{INTRODUCTION}

Congenital diaphragmatic hernia $(\mathrm{CDH})$ was first described by Lazare Riviere in a postmortem examination of a 24-year-old male (1). In 1754, George Macaulay reported the first neonate with $\mathrm{CDH}$, also in a necropsy finding in an infant who died from respiratory failure (2). Treatment successes for $\mathrm{CDH}$ appeared at the beginning of the 20th century (3), suggesting improved survival with 
early surgery (4). However, it was not until 1940, when Ladd and Gross reported 9 survivors out of 16 operated $\mathrm{CDH}$ patients (5), that surgery became an accepted treatment for CDH. In 1946, Gross also reported the first successful repair of a $\mathrm{CDH}$ in a newborn in the first $24 \mathrm{~h}$ of life (6). At that time, surgical correction of $\mathrm{CDH}$ was considered a surgical emergency and immediate repair was the mainstay of the treatment with $90-95 \%$ reported survival rates (7). Since then, the management of $\mathrm{CDH}$ has undergone many modifications, shifting from a surgical emergency to a physiologic one. Treatments such as extracorporeal membrane oxygenation (ECMO), high-frequency ventilation, inhaled nitric oxide (iNO), and minimal access surgery have been introduced and gained popularity. In the last 15-20 years, several singleinstitution studies have reported the impact of management changes on the outcome of $\mathrm{CDH}$ patients, with controversial results (8-13). The only study on treatment and outcomes changes in $\mathrm{CDH}$, involving a large cohort of patients, was published in 2006 but was limited to patients with diaphragmatic agenesis and showed no significant improvements in the outcomes (14).

The aim of present study is to report the evolution of management strategies for all newborns with high-risk $\mathrm{CDH}$ over the last two decades and to evaluate any association with changes in outcome.

\section{MATERIALS AND METHODS}

The CDH Study Group was formed in 1995 to compile data on live born infants with $\mathrm{CDH}$ at participating institutions to assess therapies and outcomes. The CDH Study Group consists of tertiary referral centers, distributed over four continents, which voluntarily provide data to a central registry (Appendix). Data on all infants with $\mathrm{CDH}$ who are born at or transferred to a participating center are entered into the database. Data are collected prospectively on all live born patients with $\mathrm{CDH}$ in participating hospitals and include information on delivery and subsequent hospital care until death or hospital discharge. The data from the registry forms are entered into a Microsoft (Redmond, WA, USA) Access database and are crosschecked against the original form. Patient demographics, birth information, treatment received, and outcome are recorded.

Patients with "high-risk" CDH (prenatal diagnosis and/or symptoms within the first $6 \mathrm{~h}$ of life) included in the Registry until December 2013 are the object of present study and are divided in three Eras (1995-2000, 2001-2006, 2007-2013). The definition of the Eras was made "a priori" and established to have three Eras of comparable length. Since 1995, there have been four versions of the data collection tool. With each update, the $\mathrm{CDH}$ Study Group has attempted to streamline information to provide an accurate reflection of the practice among individual centers. With each revision, data deemed unnecessary were eliminated and new data points were added as a result of lessons learned from previous versions. For this study, we included data that were collected throughout all the study period. Late presenters or patients with very incomplete data were excluded from the study, like outborn patients who were not referred to one of the participating centers.

\section{Primary Outcome Measure}

Survival to discharge (defined as discharge from the tertiary hospitals, either home or back to referring hospitals).

\section{Secondary Outcome Measures}

Prevalence of repair, prevalence of oxygen dependency at 30 days of life, length of mechanical ventilation, length of hospital stay.

In addition, the following variables were extracted.

\section{Severity Indicators}

Gestational age, birth weight, and prevalence of prenatal diagnosis, inborn status, chromosomal anomalies, and major associated cardiovascular malformations. Major cardiovascular anomalies included hypoplastic left heart syndrome, coarctation of the aorta, and tetralogy of Fallot. An isolated ventricular septal defect or atrial septal defect was considered minor. In addition, the probability of survival in the three Eras was calculated, using the CDH Study Group formula: probability of survival $=1-1 /\left(1+\mathrm{e}^{-\mathrm{X}}\right)$ where $-\mathrm{X}=-5.024+0.9165$ $(\mathrm{BW})+0.4512$ (Apgar5) (15). BW is the birth weight in kilograms and Apgar5 is the 5-min Apgar score in the discrete ordinate range $0-10$.

\section{Treatment Strategies}

Use of prenatal steroids, surfactant and iNO administration and ECMO, prevalence of repair, age at repair, use of minimal access surgery (either laparoscopy or thoracoscopy), type of open surgical approach (laparotomy vs thoracotomy) and minimal access surgical approach (laparoscopy vs thoracoscopy), patch repair, and of chest tube insertion.

\section{Statistical Analysis}

Data were analyzed using GraphPad Prism 5.0 Macintosh Version (GraphPad Software, San Diego, CA, USA; www.graphpad.com). One-way ANOVA was used to compare the three groups for continuous variables, Chi-squared test and Chi-squared test for trend were used for categorical variables. Results are given as mean (SE) or prevalence, as appropriate. As several null hypotheses were tested, a Sydak-adjusted significance level of 0.0027 was calculated to account for the increased possibility of type-I error. Two-sided $p$-values are reported.

The CDH Study Group registry was approved by the University of Texas-Houston Institutional Review Board (HSCMS-03-223). Participating centers filed a Waiver of Consent for data submission or signed a Data Use Agreement for a Limited Dataset.

\section{RESULTS}

In the study period, 8,603 newborns with $\mathrm{CDH}$ were prospectively enrolled in the $\mathrm{CDH}$ Study Group Registry. Late presenters (288 patients) and patients with very incomplete data (698 patients) were excluded. Therefore, 7,617 patients were included in the analysis: 2,146 in Era I; 2,572 in Era II; and 2,899 in Era III. 


\section{Primary Outcome Measures}

Overall survival to discharge slightly but significantly improved from Era I to Era III (Table 1). When each Era was compared with each other (Era I vs Era II: $p=0.3581$; Era II vs Era III: $p=0.0274$; Era I vs Era III: $p=0.0023$ ), there was a significant improvement in survival from Era I to Era III. Patients died at 18.2 (1.3) days in Era I, at 27.0 (1.8) days in Era II, and at 25.0 (1.4) days in Era III $(p=0.0002 ; p$ for trend $=0.0017)$. The impact of patients' severity on survival was also analyzed. In patients with some defined risk factors (inborn status, chromosomal anomalies, major CVM), survival rate changed but not reaching statistical significance. This was not true for patients requiring a patch repair, where we found a significant change in survival rate from 68.1 to $76.9 \%$ ( $p<0.0001 ; p$ for trend $<0.0001$ ), while those not requiring a patch had a non-significant change in survival (from 94.5 to $96.5 \% ; p=0.0597 ; p=0.0269$ ).

\section{Secondary Outcome Measures}

Among secondary outcomes, only length of hospital stay significantly changed from 44.9 (1.3) days in Era I to 53.2 (1.2) days in Era III $(p<0.0001, p$ for trend $<0.0001)$ (Table 2).

TABLE 1 | Survival data (overall and in patients with defined risk factors).

\begin{tabular}{|c|c|c|c|c|c|}
\hline \multirow[t]{3}{*}{ Variable } & Era I & Era II & Era III & \multirow[t]{3}{*}{$p$} & \multirow{3}{*}{$\begin{array}{l}p \text { for } \\
\text { trend }\end{array}$} \\
\hline & 1999-2000 & 2001-2006 & $2007-2013$ & & \\
\hline & 2,146 pts & 2,572 pts & 2,899 pts & & \\
\hline Overall survival (\%) & 67.6 & 68.9 & 71.6 & 0.0064 & 0.0019 \\
\hline $\begin{array}{l}\text { Survival of inborn } \\
\text { pts (\%) }\end{array}$ & 60.6 & 61.3 & 66.3 & 0.0080 & 0.0046 \\
\hline $\begin{array}{l}\text { Survival of pts with } \\
\text { chrom. anom. (\%) }\end{array}$ & 29.7 & 25.9 & 41.8 & 0.0146 & 0.0247 \\
\hline $\begin{array}{l}\text { Survival of pts with } \\
\text { major CVM (\%) }\end{array}$ & 30.9 & 44.2 & 40.2 & 0.0416 & 0.1418 \\
\hline $\begin{array}{l}\text { Survival of pts with } \\
\text { patch repair (\%) }\end{array}$ & 68.1 & 71.5 & 76.9 & $<0.0001$ & $<0.0001$ \\
\hline
\end{tabular}

Results are mean (standard error) or prevalence, as appropriate.

CVM, cardiovascular malformations; chrom. anom, chromosomal anomalies;

Pts, patients.

Sydak adjusted $p$-value $<0.0027$ was considered significant.

TABLE 2 | Secondary outcome measures.

\begin{tabular}{|c|c|c|c|c|c|}
\hline \multirow[t]{3}{*}{ Variable } & Era I & Era II & Era III & \multirow[t]{3}{*}{$p$} & \multirow{3}{*}{$\begin{array}{l}p \text { for } \\
\text { trend }\end{array}$} \\
\hline & \multirow{2}{*}{$\frac{1999-2000}{2,146 \text { pts }}$} & 2001-2006 & 2007-2013 & & \\
\hline & & 2,572 pts & 2,899 pts & & \\
\hline Operated patients (\%) & 82.3 & 82.3 & 83.0 & 0.7462 & 0.5062 \\
\hline $\begin{array}{l}\text { Oxygen dependency } \\
\text { at } 30 \text { days (\%) }\end{array}$ & 40.2 & 42.7 & 44.4 & 0.0365 & 0.0106 \\
\hline $\begin{array}{l}\text { Length of mechanical } \\
\text { ventilation (days) }\end{array}$ & $19.0(0.8)$ & $19.7(0.7)$ & $19.7(0.4)$ & 0.6588 & 0.4087 \\
\hline $\begin{array}{l}\text { Length of hospital } \\
\text { stay (days) }\end{array}$ & $44.9(1.3)$ & $50.3(1.2)$ & $53.2(1.2)$ & $<0.0001$ & $<0.0001$ \\
\hline
\end{tabular}

Results are mean (SE) or prevalence, as appropriate.

Pts, patients.

Sydak-adjusted p-value $<0.0027$ was considered significant.

\section{Severity Indicators}

Gestational age significantly decreased, while prevalence of prenatal diagnosis and prevalence of inborn patients significantly increased from Era I to Era III (Table 3).

\section{Treatment Strategies}

Prenatal steroids administration, iNO use, age at operation, patch closure, and use of minimal access surgery (that progressively shifted from laparoscopy to thoracoscopy) significantly rose (Table 4). Conversely, surfactant and ECMO use and chest tube placement significantly dropped.

\section{DISCUSSION}

In an analysis of over 7,500 neonates with high-risk $\mathrm{CDH}$ prospectively enrolled from multiple Institutions worldwide during the last two decades, we found that treatment strategies

TABLE 3 | Severity indicators.

\begin{tabular}{|c|c|c|c|c|c|}
\hline \multirow[t]{3}{*}{ Variable } & Era I & Era II & Era III & \multirow[t]{3}{*}{$p$} & \multirow{3}{*}{$\begin{array}{l}p \text { for } \\
\text { trend }\end{array}$} \\
\hline & \multicolumn{3}{|c|}{ 1999-2000 2001-2006 2007-2013 } & & \\
\hline & 2,146 pts & 2,572 pts & 2,899 pts & & \\
\hline $\begin{array}{l}\text { Gestational } \\
\text { age (weeks) }\end{array}$ & $37.9(0.1)$ & $37.6(0.1)$ & $37.5(0.1)$ & $<0.0001$ & $<0.0001$ \\
\hline Birth weight (grams) & $2,990(10)$ & $2,950(10)$ & $2,940(20)$ & 0.0319 & 0.0157 \\
\hline $\begin{array}{l}\text { Chromosomal } \\
\text { anomalies (\%) }\end{array}$ & 5.2 & 4.2 & 5.5 & 0.1632 & 0.5436 \\
\hline Major CVM (\%) & 6.6 & 8.4 & 8.4 & 0.0360 & 0.0332 \\
\hline Prenatal diagnosis (\%) & 47.4 & 61.4 & 67.4 & $<0.0001$ & $<0.0001$ \\
\hline Inborn (\%) & 35.4 & 43.1 & 45.2 & $<0.0001$ & $<0.0001$ \\
\hline Predicted survival (\%) & $62.7(0.5)$ & $64.7(0.5)$ & $64.2(0.4)$ & 0.0123 & 0.0125 \\
\hline
\end{tabular}

Results are mean (SE) or prevalence, as appropriate.

CVM, cardiovascular malformations.

Sydak-adjusted $p$-value $<0.0027$ was considered significant.

TABLE 4 | Treatment strategies.

\begin{tabular}{|c|c|c|c|c|c|}
\hline \multirow[t]{3}{*}{ Variable } & Era I & Era II & Era III & \multirow[t]{3}{*}{$p$} & \multirow{3}{*}{$\begin{array}{l}p \text { for } \\
\text { trend }\end{array}$} \\
\hline & 1999-2000 & 2001-2006 & 2007-2013 & & \\
\hline & 2,146 pts & 2,572 pts & 2,899 pts & & \\
\hline Prenatal steroids (\%) & 12.1 & 14.4 & 22.6 & $<0.0001$ & $<0.0001$ \\
\hline Surfactant (\%) & 29.3 & 28.9 & 15.6 & $<0.0001$ & $<0.0001$ \\
\hline $\begin{array}{l}\text { Inhaled nitric } \\
\text { oxide (\%) }\end{array}$ & 27.1 & 50.5 & 61.6 & $<0.0001$ & $<0.0001$ \\
\hline ECMO (\%) & 37.5 & 31.6 & 30.3 & $<0.0001$ & $<0.0001$ \\
\hline $\begin{array}{l}\text { Age at } \\
\text { operation (days) }\end{array}$ & $6.1(0.2)$ & $7.3(0.2)$ & $7.7(0.2)$ & $<0.0001$ & $<0.0001$ \\
\hline MAS (\%) & 0.1 & 2.1 & 15.3 & $<0.0001$ & $<0.0001$ \\
\hline $\begin{array}{l}\text { Open thoracic } \\
\text { approach (\%) }\end{array}$ & 4.2 & 4.0 & 5.3 & 0.1010 & 0.0909 \\
\hline Thoracoscopy (\%) & 0.0 & 69.9 & 90.2 & $<0.0001$ & $<0.0001$ \\
\hline Patch (\%) & 46.7 & 51.4 & 54.2 & $<0.0001$ & $<0.0001$ \\
\hline Chest tube (\%) & 65.0 & 42.8 & 34.9 & $<0.0001$ & $<0.0001$ \\
\hline
\end{tabular}

Results are mean (SE) or prevalence, as appropriate.

ECMO, extracorporeal membrane oxygenation; MAS, minimal access surgery.

Sydak-adjusted $p$-value $<0.0027$ was considered significant. 
significantly changed and survival to discharge improved, despite the severity remained stable.

In $\mathrm{CDH}$ patients, the use of prenatal steroids and surfactant is based on the opinion that their lung is immature. Both experimental and human studies showed conflicting results on surfactant components in CDH lungs (16-19). Clinically, some suggest benefits with surfactant administration, and propose its use as routine or rescue therapy $(20,21)$, while data published from the $\mathrm{CDH}$ Study Group show no significant advantage of surfactant use, both in term and preterm infants with $\mathrm{CDH}$ (22), conversely raising some concerns over its routine use (22). A potential alternative to postnatal surfactant administration is to induce lung maturation by prenatal steroids. The inverse trends of decreasing postnatal surfactant administration and increasing prenatal steroids use may be an attempt to enhance lung maturation without the risks of postnatal surfactant administration. Experimental studies suggest that prenatal steroids significantly improve both lung maturation and postnatal outcome in $\operatorname{CDH}(23,24)$. However, clinical data do not confirm the benefit of prenatal steroids administration $(11,20)$ and a recent report from the $\mathrm{CDH}$ Study Group does not support their use in CDH (25). As prenatal steroids use is not devoid of complications (26), it is prudent to confine antenatal steroids treatment in infants between 24 and 34 weeks of gestation, if delivery is expected before 34 weeks $(27,28)$.

Extracorporeal membrane oxygenation use progressively dropped, especially between Era I and Era II. ECMO is a complex and expensive technique that allows the blood to be oxygenated outside the body obviating the need for gas exchange in the lungs and is a last resort therapy in patients not responding to maximal conventional therapy. Neonates with $\mathrm{CDH}$ represent a distinct subgroup that seems to benefit less from ECMO, with a disappointing 51\% survival (29). A recent meta-analysis on both retrospective and randomized studies on ECMO use in $\mathrm{CDH}$ showed controversial results (30). The meta-analysis of retrospective studies suggested a significant benefit from ECMO, especially for the more severe patients. Only two randomized studies could be included in the meta-analysis, showing only short-term advantages. ECMO provides effective but short-term support for the respiratory failure associated with $\mathrm{CDH}$. The use of ECMO allows time for reversing the persistent pulmonary hypertension, otherwise lethal, avoiding high volume and/or pressure ventilation, which is traumatic for the lungs. However, ECMO does not have an effect on pulmonary hypoplasia and will be ineffective in patients with truly lethal pulmonary hypoplasia. As the degree of pulmonary hypoplasia cannot be foreseen accurately, the problem remains of predicting appropriate use of ECMO.

During the study period, the use of iNO progressively increased despite three different randomized controlled trials showed no benefit in patients with $\mathrm{CDH}$ (31-33). Nitric oxide is an endothelial-derived vasodilator that, inhaled, has a selective effect on the pulmonary arteries, and bronchodilator and anti-inflammatory effects. A recent Cochrane systematic review showed that iNO use resulted in prompt improvement of oxygenation and reduced the need for ECMO in neonates with persistent pulmonaryhypertension, excepting CDH patients (34). It was concluded that term or near term neonates with hypoxic respiratory failure unresponsive to other therapy should have a trial of iNO, excluding infants with $\mathrm{CDH}$. The increase seen during the study period, despite the available evidence, cannot be due to lack of awareness of the evidence. Most probably, physicians' motivation to normalize physiology prevails when faced with a hypoxic ventilated $\mathrm{CDH}$ baby. As this treatment is hugely expensive and potentially harmful (35), further studies should aim to evaluate its efficacy and standardize its application in order to optimize patient outcomes and ensure costeffective practices.

During the study period, age at operation and minimal access surgery use progressively rose. Although no clear evidence exists favoring delayed surgery in $\mathrm{CDH}$ (36), it is common belief that preoperative stabilization may improve the patients' outcome. The progressive increase of age at operation may relate to a longer time required for patients' stabilization and suggests increased severity. The progressive increase of the proportion of prenatal diagnosis, inborn patients, and patch repair, which correlate with severity and outcome $(37,38)$, are in agreement with this interpretation. One reason for this increase in severity may be the increased accuracy of prenatal diagnosis. Outborn severely ill $\mathrm{CDH}$ patients may die before transport to a tertiary referral center and hence constitute a hidden mortality. More accurate/ sensitive prenatal diagnosis results in a higher detection rate of larger defects, with stomach and/or liver in the chest, and in an increase of "in utero" transfer of severely affected patients to tertiary referral centers. This hypothesis fits well with the increasing prevalence of patch repair, a proxy of defect size, which is a robust indicator of severity as it correlates with both mortality and morbidity at discharge $(37,39,40)$. In theory, the increase in prenatal ultrasound accuracy may also lead to an increase in pregnancy termination. However, the stability of the proportion of patients with major cardiovascular anomalies and chromosomal anomalies, which are major causes inducing to termination of pregnancy, suggests that patterns of termination of pregnancy did not change over the study period. The progressive and corresponding increase in inborn patients we found over the three Eras rather corroborates the hypothesis of growing "in utero" referral of patients with prenatal diagnosis. The gradual increase of length of stay also suggests a worsening population, probably due to more demanding associated morbidities, as length of mechanical ventilation did not change over the study period. On the other hand, the disease severity, as predicted by the CDH Study Group formula (15), seemed stable over the study period.

Minimal access surgical approach progressively gained popularity, with a complete shift from laparoscopy to thoracoscopy. With its progression in the pediatric population, this approach was extended also to $\mathrm{CDH}$ patients. The comparison of minimal access surgery with open surgery for $\mathrm{CDH}$ shows controversial results, and the former was associated with higher recurrence rates (41) and intraoperative hypercapnea and acidosis (42), calling into question its safety. Consequently, its use should be cautious in patients with high-risk $\mathrm{CDH}$ and be limited to the less severe cases. 
The Survival rate slightly but significantly improved over the study period, particularly between Era I and Era III, with the trend being statistically significant, suggesting an improvement in $\mathrm{CDH}$ management. It is possible that the concomitant increase seen in the severity of patients enrolled in the CDHSG registry may have led to the limited improvement in survival recorded in this study.

However, bordering the analysis to those groups of patients recognized as more severe, the increase in survival rate is more "clinical" than "statistical." Survival increase from 61 to $66 \%$ in inborn patients, from 30 to $42 \%$ in those with chromosomal anomalies, from 31 to $40 \%$ in patients with major CVM, and from 68 to $77 \%$ in those requiring a patch. In all except those requiring a patch repair, these differences (approximating $10 \%$ improvement) did not reach statistical significance, possibly due to the design of the statistical analysis where we set the significance level well below the commonly accepted $p<0.05$. These data suggest that changes in $\mathrm{CDH}$ management may have had an impact especially in the more severely affected patients. The finding regarding the change in survival in patients requiring patch repair is in contrast with the previous report from the $\mathrm{CDH}$ Study Group on patients with diaphragmatic agenesis, which showed no improvements in terms of mortality, hospital stay, and morbidity (14). It is possible that surgeon's indication for patch repair became more liberal with time, with its use also in patients who would have undergone primary repair in the earlier years. On the other hand, the previous study was "limited" to 10 years while present study has a longer time span, allowing more time for treatment changes to influence the outcomes. The history of $\mathrm{CDH}$ outcome reporting shows bipolar courses with cycles of enthusiasm and nihilism. The majority of the reports derive from single tertiary referral institutions. This may lead to case selection bias and the existence of a "hidden mortality," which is difficult to quantify (43). Outcomes analyzed at a supra-Institution level show a slight but significant improvement in the long run. The improvements in outcomes have been in turn attributed to the introduction of new treatment modalities. However, randomized studies, failed to show any true impact of their use, singularly, on the outcomes of $\mathrm{CDH}$ patients (31-33, 44-46). Most of these studies were not specifically designed for $\mathrm{CDH}$ patients, analyzed only as relatively small subgroups. Therefore, it is possible that they were not powered enough to detect the effects of the investigated treatments, if present. An alternative explanation is that the single intervention examined was not able to cause significant changes in the outcome by itself. In our cohort, a combined effect of several interventions cannot be excluded. Additionally, it is possible that other strategies that we were not able to assess, because not recorded in the registry, may have had an impact on survival evolution. The several changes in treatment strategies that happened during the last two decades combined together may have led to the improvement in survival rate seen in high-risk $\mathrm{CDH}$ patients enrolled in the CDH Study Group registry.

The CDH Registry was formed to allow collection and analysis of data on treatment and outcomes of infants with $\mathrm{CDH}$ from a large number of centers. While registries have proven to be a good way to collect information on various disorders, care should be taken in interpreting the data. In addition, they allow the analysis only on collected data, and we have limited the analysis only to data collected all along the study period. For example, data on the use of gentle ventilation, which was an important change introduced in the 1990s (47), are not recorded in the Registry and some of the data used to assess severity such as observed to expected lung to head ratio, the presence of the liver in the chest, or data used in the Brindle's clinical prediction rule (48), were recorded only during the third Era. This may cause some uncertainity in the interpretation of the severity of patients groups in the three Eras. On the other hand, despite its limitations, present study allows the description of changes over a very long period, on a huge number of patients, which would have been impossible without a tool such as the Registry. The database is observational and conclusions about therapies should be made cautiously. The data are collected from institutions that differ significantly in their patient referral base and their criteria for accepting an infant with $\mathrm{CDH}$ for admission. Criteria for "non-salvageable" patients vary between centers and some patients in the repaired group in one center may not have undergone operation in another. Many infants with severe cardiac and chromosomal anomalies did not undergo repair making the true impact of these factors difficult to determine. There are also variations in surgical practice that may determine differences in timing of surgery and whether a patch is used. Similarly, the definition of agenesis is likely to vary somewhat between centers. Finally, the definition of the Eras was not based on the commencement or change in frequency use of each single treatment analyzed. However, this study is not designed to define the impact of one single treatment on the outcome of $\mathrm{CDH}$. Rather, this study describes how treatment strategies used in $\mathrm{CDH}$ patients changed in the last decades and if this change was accompanied by a change in their outcome. While the characteristics of the registry does not allow to define the effects of a single treatment, its international and supra-Institutional nature is ideal to describe the changes in treatment strategies and overall trends of the outcomes. The observations of such a registry can be considered valid because they are free from single Institutions biases and policies are not driven by superimposed protocols. In addition, the huge number of patients enrolled gives further strength to the study leading to reliable interpretations and meaningful conclusions.

\section{CONCLUSION}

The analysis of over 7,500 high-risk $\mathrm{CDH}$ patients shows several changes in the treatment strategies over the study period. During the same period, survival rate slightly but significantly improved, despite the patients' population remained stable. Most of these changes were adopted based on common opinion rather than on evidence. Despite none of the treatments introduced represents per se the quested "magic bullet" in high-risk $\mathrm{CDH}$ management, a combined effect may be responsible for the improvements recorded. Data on long-term outcomes are currently missing from the registry. However, they would deserve attention to define if changes in early management of $\mathrm{CDH}$ patients have an impact on their long-term prognosis. 


\section{AUTHOR CONTRIBUTIONS}

FM conceptualized and designed the study, carried out the initial analyses, drafted, reviewed and revised the manuscript, and approved the final manuscript as submitted. KL designed the data collection instruments, conceptualized and designed the study, critically reviewed the manuscript, and approved the final manuscript as submitted. PL designed the data collection instruments, coordinated and supervised data collection, reviewed and revised the manuscript, and approved the final manuscript as submitted. RC and IC reviewed and revised the manuscript, critically reviewed the manuscript, and approved the final manuscript as submitted. PB conceptualized and designed the

\section{REFERENCES}

1. Riverius L. Observatio LXVII: Situs ventriculi monstruosus. In: Riverius L, Jacoz S, editors. Observationum Medicarum \& Curationum Insignum. Centuria Quarta. Hagae Comitum: Apud Adrianum Vlacq (1662). 39 p.

2. Macaulay G. An account of a child whose abdominal viscera were chiefly found within the cavity of the thorax. Med Obs Inquiries (1757) 1:26-30.

3. Heidenhain L. Geschichte eines falles von chronischer incarceration des Magens in einer angeborenen zwerchfellhernie welcher durch laparotomie geheilt wurde mit anschliessende bemerkungen tiber die moglichkeit das kardiacarcinom der speiseröhre zu resesziren. Deutsch Z Chir (1905) 76:394-403. doi:10.1007/BF02791475

4. Hedblom CA. Diaphragmatic hernia. A study of three hundred and seventyeight cases in which operation was performed. JAMA (1925) 85:947-53. doi:10.1001/jama.1925.02670130009003

5. Ladd WE, Gross RE. Congenital diaphragmatic hernia. N Engl J Med (1940) 223:917-25. doi:10.1056/NEJM194012052232301

6. Gross RE. Congenital hernia of the diaphragm. Am J Dis Child (1946) 71:579-92. doi:10.1001/archpedi.1946.02020290002001

7. Gross RE. Congenital hernia of the diaphragm. In: Gross RE, editor. The Surgery of Infancy and Childhood: Its Principles and Techniques. Philadelphia, PA: WB Saunders (1953). p. 428-44.

8. Azarow K, Messineo A, Pearl R, Filler R, Barker G, Bohn D. Congenital diaphragmatic hernia - a tale of two cities: the Toronto experience. J Pediatr Surg (1997) 32:395-400. doi:10.1016/S0022-3468(97)90589-3

9. Wilson JM, Lund DP, Lillehei CW, Vacanti JP. Congenital diaphragmatic hernia - a tale of two cities: the Boston experience. J Pediatr Surg (1997) 32:401-5. doi:10.1016/S0022-3468(97)90590-X

10. Weber TR, Kountzman B, Dillon PA, Silon ML. Improved survival in congenital diaphragmatic hernia with evolving therapeutic strategies. Arch Surg (1998) 133:498-502. doi:10.1001/archsurg.133.5.498

11. Kays DW, Langham MR Jr, Ledbetter DJ, Talbert JL. Detrimental effects of standard medical therapy in congenital diaphragmatic hernia. Ann Surg (1999) 230:340-8. doi:10.1097/00000658-199909000-00007

12. Stege G, Fenton A, Jaffray B. Nihilism in the 1990s: the true mortality of congenital diaphragmatic hernia. Pediatrics (2003) 112:532-5. doi:10.1542/ peds.112.3.532

13. Downard CD, Jaksic T, Garza JJ, Dzakovic A, Nemes L, Jennings RW, et al. Analysis of an improved survival rate for congenital diaphragmatic hernia. J Pediatr Surg (2003) 38:729-32. doi:10.1016/jpsu.2003.50194

14. Lally KP, Lally PA, Van Meurs KP, Bohn DJ, Davis CF, Rodgers B, et al. Treatment evolution in high-risk congenital diaphragmatic hernia. Ten years' experience with diaphragmatic agenesis. Ann Surg (2006) 244:505-13. doi:10.1097/01.sla.0000239027.61651.fa

15. Lally KP, Jaksic T, Wilson JM, Clark RH, Hardin WD Jr, Ronald Hirschl RB, et al. Estimating disease severity of congenital diaphragmatic hernia in the first 5 minutes of life. J Pediatr Surg (2001) 36:141-5. doi:10.1053/jpsu. 2001.20032

16. Van Tuyl M, Blommaart PJ, Keijzer R, Wert SE, Ruijter J, Lamers WH, et al. Pulmonary surfactant protein $\mathrm{A}, \mathrm{B}$, and $\mathrm{C}$ mRNA and protein expression in the nitrofen-induced congenital diaphragmatic hernia rat model. Pediatr Res (2003) 54:641-52. doi:10.1203/01.PDR.0000086906.19683.42 study, critically reviewed the manuscript, and approved the final manuscript as submitted. All authors agree to be accountable for all aspects of the work in ensuring that questions related to the accuracy or integrity of any part of the work are appropriately investigated and resolved.

\section{ACKNOWLEDGMENTS}

We would like to acknowledge the ongoing contributions of highly committed Congenital Diaphragmatic Hernia Study Group members who voluntarily participate in the study of congenital diaphragmatic hernia.

17. Brandsma AE, Tibboel D, Vulto IM, Egberts J, Ten Have-Opbroek AA Ultrastructural features of alveolar epithelial cells in the late fetal pulmonary acinus: a comparison between normal and hypoplastic lungs using a rat model of pulmonary hypoplasia and congenital diaphragmatic hernia. Microsc Res Tech (1993) 26:389-99. doi:10.1002/jemt.1070260507

18. Asabe K, Tsuji K, Handa N, Kurosaka N, Kajiwara M. Immunohistochemical distribution of surfactant apoprotein-A in congenital diaphragmatic hernia. J Pediatr Surg (1997) 32:667-72. doi:10.1016/S0022-3468 (97)90001-4

19. Ijsselstijn H, Zimmermann LJ, Bunt JE, de Jongste JC, Tibboel D. Prospective evaluation of surfactant composition in bronchoalveolar lavage fluid of infants with congenital diaphragmatic hernia and of age-matched controls. Crit Care Med (1998) 26:573-80. doi:10.1097/00003246-19980300000035

20. Finer NN, Tierney A, Etches PC, Peliowski A, Ainsworth W. Congenital diaphragmatic hernia: developing a protocolized approach. J Pediatr Surg (1998) 33:1331-7. doi:10.1016/S0022-3468(98)90001-X

21. Somaschini M, Locatelli G, Salvoni L, Bellan C, Colombo A. Impact of new treatments for respiratory failure on outcome of infants with congenital diaphragmatic hernia. Eur J Pediatr (1999) 158:780-4. doi:10.1007/ s004310051203

22. Lally KP, Lally PA, Langham MR, Hirschl R, Moya FR, Tibboel D, et al. Surfactant does not improve survival rate in preterm infants with congenital diaphragmatic hernia. J Pediatr Surg (2004) 39:829-33. doi:10.1016/j. jpedsurg.2004.02.011

23. Suen HC, Bloch KD, Donahoe PK. Antenatal glucocorticoid corrects pulmonay immaturity in experimentally induced congenital diaphragmatic hernia in rats. Pediatr Res (1994) 35:523-9. doi:10.1203/00006450-19940500000002

24. Schnitzer JJ, Hedrick HL, Pacheco BA, Losty PD, Ryan DP, Doody DP, et al. Prenatal glucocorticoid therapy reverses pulmonary immaturity in congenital diaphragmatic hernia in fetal sheep. Ann Surg (1996) 224:430-7. doi:10.1097/00000658-199610000-00002

25. Lally KP, Bagolan P, Hosie S, Lally PA, Stewart M, Cotten CM, et al. Corticosteroids for fetuses with congenital diaphragmatic hernia: can we show benefit? J Pediatr Surg (2006) 41:668-74. doi:10.1016/j.jpedsurg.2005 12.007

26. McLaughlin KJ, Crowther CA, Walker N, Harding JE. Effects of a single course of corticosteroids given more than 7 days before birth: a systematic review. Aust N Z J Obstet Gynaecol (2003) 43:101-6. doi:10.1046/j.0004-8666.2003. 00052.x

27. NIH consensus development panel on the effect of corticosteroids for fetal maturation on perinatal outcomes. Effect of corticosteroids for fetal maturation on perinatal outcomes. JAMA (1995) 273:413-8. doi:10.1001/ jama.1995.03520290065031

28. National Institutes of Health Consensus Development Panel. Antenatal corticosteroids revisited: repeat courses - National Institutes of Health Consensus Development Conference Statement, August 17-18, 2000. Obstet Gynecol (2001) 98:144-50. doi:10.1097/00006250-200107000-00027

29. Paden ML, Conrad SA, Rycus PT, Thiagarajan RR; ELSO Registry. Extracorporeal Life Support Organization Registry Report 2012. ASAIO J (2013) 59:202-10. doi:10.1097/MAT.0b013e3182904a52 
30. Morini F, Goldman A, Pierro A. Extracorporeal membrane oxygenation in infants with congenital diaphragmatic hernia: a systematic review of the evidence. Eur J Pediatr Surg (2006) 16:385-91. doi:10.1055/s-2006924751

31. The Neonatal Inhaled Nitric Oxide Study Group (NINOS). Inhaled nitric oxide and hypoxic respiratory failure in infants with congenital diaphragmatic hernia. Pediatrics (1997) 99:838-45. doi:10.1542/peds.99. 6.838

32. Kinsella JP, Truog WE, Walsh WF, Goldberg RN, Bancalari E, Mayock DE, et al. Randomized, multicenter trial of inhaled nitric oxide and high-frequency oscillatory ventilation in severe, persistent pulmonary hypertension of the newborn. J Pediatr (1997) 131:55-62. doi:10.1016/S0022-3476(97) 70124-0

33. Clark RH, Kueser TJ, Walker MW, Southgate WM, Huckaby JL, Perez JA, et al. Low-dose nitric oxide therapy for persistent pulmonary hypertension of the newborn. Clinical Inhaled Nitric Oxide Research Group. $N$ Engl J Med (2000) 342:469-74. doi:10.1056/NEJM200002173420704

34. Finer N, Barrington KJ. Nitric oxide for respiratory failure in infants born at or near term. Cochrane Database Syst Rev (2006) 4:CD000399. doi:10.1002/ 14651858.CD000399.pub2

35. Putnam LR, Tsao K, Morini F, Lally PA, Miller CC, Lally KP, et al. Variability in inhaled nitric oxide use and pulmonary hypertension in patients with congenital diaphragmatic hernia. JAMA Pediatr (2016) 170:1188-94. doi:10.1001/jamapediatrics.2016.2023

36. Moyer V, Moya F, Tibboel R, Losty P, Nagaya M, Lally KP. Late versus early surgical correction for congenital diaphragmatic hernia in newborn infants. Cochrane Database Syst Rev (2002) 3:CD001695. doi:10.1002/14651858. CD001695

37. Congenital Diaphragmatic Hernia Study Group; Lally KP, Lally PA, Lasky RE, Tibboel D, Jaksic T, et al. Defect size determines survival in infants with congenital diaphragmatic hernia. Pediatrics (2007) 120:e651-7. doi:10.1542/peds.2006-3040

38. Wynn J, Krishnan U, Aspelund G, Zhang Y, Duong J, Stolar CJ, et al. Outcomes of congenital diaphragmatic hernia in the modern era of management. J Pediatr (2013) 163:114-9. doi:10.1016/j.jpeds.2012.12.036

39. Valfre L, Braguglia A, Conforti A, Morini F, Trucchi A, Iacobelli BD, et al. Long term follow-up in high-risk congenital diaphragmatic hernia survivors: patching the diaphragm affects the outcome. J Pediatr Surg (2011) 46:52-6. doi:10.1016/j.jpedsurg.2010.09.061

40. Peetsold MG, Kneepkens CM, Heij HA, IJsselstijn H, Tibboel D, Gemke RJ. Congenital diaphragmatic hernia: long-term risk of gastroesophageal reflux disease. J Pediatr Gastroenterol Nutr (2010) 51:448-53. doi:10.1097/MPG. 0b013e3181d1b149
41. Tsao K, Lally PA, Lally KP; Congenital Diaphragmatic Hernia Study Group. Minimally invasive repair of congenital diaphragmatic hernia. JPediatr Surg (2011) 46:1158-64. doi:10.1016/j.jpedsurg.2011.03.050

42. Bishay M, Giacomello L, Retrosi G, Thyoka M, Garriboli M, Brierley J, et al. Hypercapnia and acidosis during open and thoracoscopic repair of congenital diaphragmatic hernia and esophageal atresia: results of a pilot randomized controlled trial. Ann Surg (2013) 258:895-900. doi:10.1097/ SLA.0b013e31828fab55

43. Harrison MR, Adzick NS, Estes JM, Howell LJ. A prospective study of the outcome for fetuses with diaphragmatic hernia. JAMA (1994) 271:382-4. doi:10.1001/jama.1994.03510290064038

44. Bennett CC, Johnson A, Field DJ, Elbourne D; UK Collaborative ECMO Trial Group. UK collaborative randomised trial of neonatal extracorporeal membrane oxygenation: follow-up to age 4 years. Lancet (2001) 357:1094-6. doi:10.1016/S0140-6736(00)04310-5

45. Harrison MR, Keller RL, Hawgood SB, Kitterman JA, Sandberg PL, Farmer DL, et al. A randomized trial of fetal endoscopic tracheal occlusion for severe fetal congenital diaphragmatic hernia. N Engl J Med (2003) 349:1916-24. doi:10.1056/NEJMoa035005

46. Snoek KG, Capolupo I, van Rosmalen J, Hout L de J, Vijfhuize S, Greenough A, et al. Conventional mechanical ventilation versus high-frequency oscillatory ventilation for congenital diaphragmatic hernia: a randomized clinical trial (the VICI-trial). Ann Surg (2016) 263:867-74. doi:10.1097/SLA. 0000000000001533

47. Wung JT, Sahni R, Moffitt ST, Lipsitz E, Stolar CJ. Congenital diaphragmatic hernia: survival treated with very delayed surgery, spontaneous respiration, and no chest tube. J Pediatr Surg (1995) 30:406-9. doi:10.1016/ 0022-3468(95)90042-X

48. Brindle ME, Cook EF, Tibboel D, Lally PA, Lally KP; Congenital Diaphragmatic Hernia Study Group. A clinical prediction rule for the severity of congenital diaphragmatic hernias in newborns. Pediatrics (2014) 134:e413-9. doi:10.1542/peds.2013-3367

Conflict of Interest Statement: The authors declare that the research was conducted in the absence of any commercial or financial relationships that could be construed as a potential conflict of interest.

Copyright (C) 2017 Morini, Lally, Lally, Crisafulli, Capolupo and Bagolan. This is an open-access article distributed under the terms of the Creative Commons Attribution License (CC BY). The use, distribution or reproduction in other forums is permitted, provided the original author(s) or licensor are credited and that the original publication in this journal is cited, in accordance with accepted academic practice. No use, distribution or reproduction is permitted which does not comply with these terms. 


\section{APPENDIX}

TABLE A1 | Tertiary referral centers that voluntarily provided data to the CDH Study Group Registry between 1995 and 2013.

\begin{tabular}{|c|c|}
\hline Hospital & Country \\
\hline Advocate Lutheran General Hospital & USA \\
\hline Alberta Children's Hospital & Canada \\
\hline Arkansas Children's Hospital & USA \\
\hline Astrid Lindgren Children's Hospital & Sweden \\
\hline Azienda Ospedaliera Papa Giovanni XXIII & Italy \\
\hline BC Children's \& Women's Health Centre & Canada \\
\hline Cardinal Glennon Children's Hospital & USA \\
\hline Carolinas Medical Center, Levine Children's Hospital & USA \\
\hline Cedars Sinai Medical Center & Los Angeles \\
\hline Central Hospital Aichi Prefectural Colony & Japan \\
\hline Children's Hospital \& Research Center Oakland & USA \\
\hline Childrens Hospital at Skanes University Hospital & Sweden \\
\hline Children's Hospital Boston & USA \\
\hline Children's Hospital of Akron & USA \\
\hline Children's Hospital of Austin & USA \\
\hline Children's Hospital of Buffalo & USA \\
\hline Children's Hospital of Illinois & USA \\
\hline Children's Hospital of Los Angeles & USA \\
\hline Children's Hospital of Michigan & USA \\
\hline Children's Hospital of Oklahoma & USA \\
\hline Children's Hospital of Philadelphia & USA \\
\hline Children's Hospital of Wisconsin & USA \\
\hline Children's Hospital Omaha & USA \\
\hline Children's Hospitals and Clinics (Minneapolis) & USA \\
\hline Children's Memorial Hermann Hospital & USA \\
\hline Children's Mercy Hospitals \& Clinics & USA \\
\hline Children's National Medical Center & USA \\
\hline Cincinnati Children's Hospital Medical Center & USA \\
\hline Cleveland Clinic Foundation- Children's Hospital & USA \\
\hline Connecticut Children's Medical Center & USA \\
\hline Cook Children's Medical Center & USA \\
\hline Duke University Medical Center & USA \\
\hline Emory University & USA \\
\hline Freie Universitat Berlin & Germany \\
\hline Georgia Health Sciences University & USA \\
\hline Golisano Children's Hospital at Strong & USA \\
\hline Hasbro Children's Hospital, Brown Medical School & USA \\
\hline Helen DeVos Children's Hospital & USA \\
\hline Hershey Medical Center & USA \\
\hline Hospital Clinico Universidad Católica de Chile & Chile \\
\hline IRCCS Fondazione Ca' Granda Ospedale Maggiore Policlinico & Italy \\
\hline James Whitcomb Riley Children's Hospital & Indianapolis \\
\hline Juan P. Garrahan Children Hospital & Argentina \\
\hline Kosair Children's Hospital & USA \\
\hline Le Bonheur Children's Medical Center & USA \\
\hline Legacy Emanuel Children’s Hospital & USA \\
\hline Loma Linda University Children's Hospital & USA \\
\hline Lucile Salter Packard Children's Hospital & USA \\
\hline Massachusetts General Hospital & USA \\
\hline Mattel Children's Hospital at UCLA & USA \\
\hline Mayo Clinic & USA \\
\hline Medical College of Virginia & USA \\
\hline Medical University of South Carolina & USA \\
\hline
\end{tabular}

(Continued)
TABLE A1 | Continued

\begin{tabular}{|c|c|}
\hline Hospital & Country \\
\hline Miami Valley Hospital & USA \\
\hline National Center for Child Health and Development & Japan \\
\hline NICU Health Sciences Centre & Canada \\
\hline North Carolina Baptist Hospital & USA \\
\hline Ospedale Pediatrico Bambino Gesù & Italy \\
\hline Osaka Medical Center for Maternal and Child Health & Japan \\
\hline Osaka University Graduate School of Medicine & Japan \\
\hline Palmetto Health Richland & USA \\
\hline Phoenix Children's Hospital & USA \\
\hline Polish Mother's Memorial Hospital Research Institute & Poland \\
\hline Primary Children's Hospital & USA \\
\hline Radboud University Nijmegen Medical Centre & The Netherlands \\
\hline Rainbow Babies and Children Hospital & USA \\
\hline Research Center for Obstetrics, Gynecology and Perinatology & Russia \\
\hline Research Institute at Nationwide Children's Hospital & USA \\
\hline Rockford Memorial Children's Hospital & USA \\
\hline Royal Alexandra Hospital & Canada \\
\hline Royal Children's Hospital & Australia \\
\hline Royal Hospital for Sick Children & Scotland \\
\hline Salesi Children's Hospital & Italy \\
\hline San Diego Children's Hospital & USA \\
\hline Santa Rosa Children’s Hospital & USA \\
\hline Shands Children's Hospital/University of Florida & USA \\
\hline Sophia Children's Hospital & The Netherlands \\
\hline St. Christopher's Children's Hospital & USA \\
\hline St. Francis Children's Hospital & USA \\
\hline St. Joseph's Hospital and Medical Center & USA \\
\hline St. Louis Children's Hospital & USA \\
\hline St. Paul Campus Children's Minneapolis & USA \\
\hline Stollery Children's Hospital & Canada \\
\hline Sydney Children's Hospital & Australia \\
\hline T.C. Thompson Hospital & USA \\
\hline Texas Children's Hospital & USA \\
\hline The Children's Hospital of Alabama & USA \\
\hline The Children's Hospital of Pittsburgh of UPMC & USA \\
\hline The Hospital for Sick Children & Canada \\
\hline Tulane University Hospital & USA \\
\hline UNC School of Medicine & USA \\
\hline Universitatsklinikum Mannheim gGmbH & Germany \\
\hline University Hospital Gasthuisberg & Belgium \\
\hline University Malaya Medical Centre & Malaysia \\
\hline University of California San Diego & USA \\
\hline University of Chicago & USA \\
\hline University of Kentucky Medical Center & USA \\
\hline University of Michigan, C.S. Mott Children's Hospital & USA \\
\hline University of Mississippi Medical Center & USA \\
\hline University of Nebraska Medical Center & USA \\
\hline University of New Mexico Children's Hospital & USA \\
\hline University of Padua & Italy \\
\hline University of Puerto Rico Medical Center & USA \\
\hline University of Texas Medical Branch at Galveston & USA \\
\hline University of Virginia Medical School & USA \\
\hline Vanderbilt Children's Hospital & USA \\
\hline Vladivostok State Medical University & Russia \\
\hline Wilford Hall USAF Medical Center & USA \\
\hline Winnie Palmer Hospital for Women \& Babies & USA \\
\hline Yale New Haven Children's Hospital & USA \\
\hline
\end{tabular}

